\title{
Making Arm Movements within Different Parts of Space: The Premotor and Motor Cortical Representation of a Coordinate System for Reaching to Visual Targets
}

\author{
R. Caminiti, ${ }^{1}$ P. B. Johnson, ${ }^{2}$ C. Galli, ${ }^{1}$ S. Ferraina, ${ }^{1}$ and Y. Burnod $^{3}$ \\ 1 Istituto di Fisiologia umana, Facoltà di Medicina e Chirurgia, Università degli Studi di Roma "La Sapienza," P.le A. Moro \\ 5, 00185 Rome Italy, ${ }^{2}$ Curriculum in Neurobiology, University of North Carolina, Chapel Hill, North Carolina 27599, and \\ 3Départment de Neurosciences de la Vision, Institut des Neurosciences, Université Paris VI, 9 quai St. Bernard, Paris, \\ 75005 France
}

The activity of 156 individual arm-related neurons was studied in the premotor cortex (area 6) while monkeys made arm movements of similar directions within different parts of 3-dimensional space. This study was aimed at describing the relationship between premotor cortical cell activity and direction of arm movement and assessing the coordinate system underlying this relationship.

We found that the activity of $152(97.4 \%)$ cells varied in an orderly fashion with the direction of movement, in at least some region of the work space. Premotor cortical cells fired most for a given preferred direction and less for other directions of movement. These preferred directions covered the directional continuum in a uniform fashion across the work space. It was found that, as movements of similar directions were made within different parts of the work space, the cells' preferred directions changed their orientation. Although these changes had different magnitudes for different cells, at the population level, they followed closely the changes in orientation of the arm necessary to move the hand from one to another part of the work space.

This shift of cells' preferred direction with the orientation of the arm in space has been observed with similar characteristics in the motor cortex (see Caminiti et al., 1990).

In both premotor and motor cortices, neuronal movement population vectors provide a good description of movement direction. Unlike the individual cell preferred directions upon which they are based, movement population vectors did not change their spatial orientation across the work space, suggesting that they remain good predictors of movement direction regardless of the region of space in which movements are made.

The firing frequency of both premotor and motor cortical neurons varied significantly with the position occupied by

\footnotetext{
Received May 25, 1990; revised Nov. 16, 1990; accepted Nov. 20, 1990.

This work was supported by The European Economic Community (Grant SCI 0028-c/A), the Consiglio Nazionale delle Ricerche, Rome, Italy, and by USPHS Grant NS07166. We are grateful to L. Ercolani for her assistance during the experiments and in the preparation of this manuscript. Special thanks for the assistance of C. Hill at the Graphics Laboratory of the Department of Computer Science, University of North Carolina, Chapel Hill.

Correspondence should be addressed to Roberto Caminiti, Istituto di Fisiologia umana, Facoltà di Medicina e Chirurgia, Università degli Studi di Roma "La Sapienza," P.le A. Moro 500185 Rome, Italy.

Part of this work has been presented as a preliminary research note [Exp Brain Res (1990) 83:228-232].

Copyright (C) 1991 Society for Neuroscience $0270-6474 / 91 / 111182-16 \$ 03.00 / 0$
}

the hand in space. These static positional effects were observed in $\mathbf{8 8 . 5} \%$ of premotor and $\mathbf{9 1 . 8} \%$ of motor cortical cells.

In a second task, monkeys made movements from differing origins to a common end point. This task was performed within 3 different parts of space and was aimed at dissociating movement direction from movement end point. It was found that in both premotor and motor cortices virtually all cells were related to the direction and not to the end point of movement.

These data suggest that premotor and motor cortices use common mechanisms for coding arm movement direction. They also provide a basis for understanding the coordinate transformation required to move the hand toward visual targets in space.

In the last 10 years, many neurophysiological studies have been devoted to the analysis of the relations between neuronal activity and direction of arm movement in the primary motor cortex (area 4). These studies (Georgopoulos et al., 1982, 1986; Schwartz et al., 1988), using 2- and 3-dimensional (2-D, 3-D) reaching tasks, have shown that when an animal makes arm movements of different directions in space, cell activity in the motor cortex varies in an orderly fashion with the direction of movement. Subsequent studies (Kalaska and Hyde, 1985; Kalaska et al., 1989) have been centered on the influence of kinematic and dynamic aspects of movement on neural activity in area 4 . While showing that in this area there exists an interaction between direction of movement and direction of force, the work of $\mathrm{Ka}$ laska and his colleagues has also indicated how "resistant" the directional information is to differences in the amount of force exerted during arm movements. Other works have shown, in addition, that movement amplitude affects only cells possessing directional selectivity (Schwartz and Georgopoulos, 1987), with the specification of movement direction as a prerequisite for the coding of movement amplitude (Riehle and Requin, 1989). All these studies stress the importance of movement direction as a coded parameter of motor cortical cell activity. This raises related questions concerning the coordinate system used by the frontal cortex to represent arm movement direction. In a previous study (Caminiti et al., 1990), we have shown that when an animal makes arm movements of approximately parallel directions within different parts of a 3-D space the orientation of motor cortical cell preferred directions follows the changes in the orientation of the arm necessary to bring the hand within 
different parts of the work space. This suggests that area 4 represents arm movement direction within a coordinate system centered on the shoulder joint. This coding mechanism would be of more general importance if its existence could be demonstrated in other cortical areas, such as the dorsal premotor cortex, which, on other grounds, shows profound differences from the motor cortex (for a review, see Brinkman and Porter, 1983; Wisc, 1984, 1985). The usc of common mechanisms could be important for facilitating the transformation of directionrelated information between different areas of the distributed cortical network of the frontal lobe. Furthermore, their existence may aid in the understanding of how information from different domains of representation are brought to a common frame of reference as is required for the performance of a reaching movement to a visual target in space.

We studied the premotor cortex of monkeys using the same methodological approach adopted in a previous study of the motor cortex (Caminiti et al., 1990). The activity of individual neurons was recorded in area 6 while animals made approximately parallel arm movements within different parts of space. Because these movement directions were parallel only in the Cartesian coordinates of extrapersonal space, and corresponded to different angles of the shoulder joint when considered in an intrinsic body space, the task was aimed at dissociating cxtrinsic from intrinsic coordinate systems. Other behavioral tasks were used to dissociate movement direction from movement end point and to assess the influence of static spatial factors concerning the orientation of the arm in space on cortical activity.

\section{Materials and Methods}

Behavioral apparatus. The behavioral apparatus consisted of 19 metal rods placed in front of and oriented toward the monkey (see Caminiti et al., 1990). Each rod was fitted on the end with a $1-\mathrm{cm}$ diameter transparent plastic push button. Each push button could be illuminated from behind by a red light emitting diode (LED). Sixteen of the push buttons were arranged in space so as to form 3 adjacent, contiguous imaginary cubes (Fig. 1). The remaining 3 push buttons were situated at the centers of these 3 cubes. The buttons at the vertices of each cube were placed $10 \mathrm{~cm}$ from one another and $8.7 \mathrm{~cm}$ from the ccnter button of that cube. The center button of the center cube was located in the midsagittal plane at shoulder height and $25 \mathrm{~cm}$ from the animal (Fig. 1). During recording sessions, the animal sat in a primate chair with the head fixed and thus made free arm reaching movements with limited motion of the torso.

Animals and task. Two adult female Macaca nemestrina monkeys ( 3.2 and $3.5 \mathrm{~kg}$ body weight) were used in this study. Data concerning Task 2 and static positional effects in motor cortex (area 4 ) were collected during a previous study (Caminiti et al., 1990) where 3 female Macaca nemestrina monkeys ( $3-4 \mathrm{~kg}$ body weight) performing various tasks were used. New data from the motor cortex were obtained from an additional monkey. The monkeys were trained to perform free-arm reaching movements to visual targets in 3-D space. Two distinct but similar tasks were used in this study.

In Task 1 (Fig. 1), reaching movements were made from common starting points to targets distributed in 3-D space. After a variable intertrial interval (ITI; $1-1.5 \mathrm{sec}$ ) a trial was initiated by the illumination of the center button of the central cube. The monkey was required to press and hold the illuminated button (control button) for a randomly variable control time (CT; $1.5-2.5 \mathrm{sec}$ ) until the center LED was extinguished and 1 of the target buttons at the vertices of the central cube was illuminated. Within specified upper limits of reaction time (RT; $350 \mathrm{msec}$ ) and movement time (MT; $1 \mathrm{sec}$ ) the animal was required to release the control button and then depress the target button. After a variable target holding time (THT; $1-1.5 \mathrm{sec}$ ) during which the animal was required to maintain pressing the target button, a liquid reward was delivered. Targets were presented in a pseudorandom sequence until 5 movements were correctly performed to each of the 8 targets of the center cube. Movements were then repeated in the left and right cubes. The order of cube presentation was often changed.
Thus, within any 1 cube, the monkeys made movements in 8 different directions. Because of the side-by-side arrangement of the cubes, the 8 different directions in any 1 cube were parallel to the 8 different movement directions in both of the other cubes but occurred within different regions of extrapersonal space.

In Task 2 (Fig. 1), movements were made from varying starting positions to common end points. Task 2 is the converse of Task 1 in that movements were made from push buttons at the vertices of a cube to the button at the center of that cube. After a variable ITI, a button at 1 of the vertices of the central cube was chosen at random and illuminated. The monkey was required to press and hold the illuminated button (control button) until it was turned off (control time) and the center LED was turned on. Within specified RT and MT the monkey was required to depress the center button. After the THT, a liquid reward was delivered. Similarly to Task 1 , buttons were illuminated in a pseudorandom fashion until 5 movements from each of the 8 starting positions were correctly performed. The movements were then repeated on the left and right cubes. The time limits on the various cpochs of the task were the same as those used in Task 1.

Trajectory recording. The movements in space of the arm were recorded using an ultrasonic tracking system, as explained in detail elsewhere (Caminiti et al., 1990).

Neural recording. The procedures used for neural recording have been reported previously (Caminiti et al., 1990). The electrical activity of premotor cortical neurons was recorded extracellularly.

A qualitative examination of the animal was performed for each isolated action potential in an effort to determine whether the cell's activity was related to arm movements at the shoulder and/or elbow joints and to determine the presence and quality of passive inputs to the cell from skin, deep tissues, muscles, and joints. The objective of the qualitative examination was to select for further study only those cells that were related to proximal arm movements. This was deemed appropriate because the task involves primarily proximal musculature (see Caminiti et al., 1990), and also to allow a direct comparison with proximal arm related cells recorded in the motor cortex. All recordings were made in the hemisphere contralateral to the performing arm. Data from the right hemisphere were mirror-transformed to allow the analysis of all cells as if they were recorded from the left hemisphere (right arm).

Data acquisition. Control of the behavioral task and collection of all data, performed by a PDP $11 / 23$ + minicomputer, were the same as reported in a previous study (Caminiti et al., 1990) to which the reader is referred for details.

Quantitative data analysis. For the subsequent quantitative analyses, each trial was divided into 4 epochs: the control time (CT) was the last $1 \mathrm{sec}$ that the animal held the control button prior to the presentation of the target; the reaction time (RT) extended from the presentation of the target until the release of the control button; the movement time (MT) was defined as the time from the release of the control button until the target button was depressed; the target hold time (THT) was the time from when the target button was pressed until the reward was delivered. A fifth epoch, the total experimental time (TET) was defined as the combination of the RT and MT. As measures of the activity of individual cells, for each cell and each trial, the mean firing frequency was calculated during each of these epochs.

Analysis of the directional properties of neurons. For each cell-cube combination an ANOVA was performed on the mean firing frequency during the TET to determine whether the neuron varied its activity with movements of differing directions. Cells with significant direction effects $(p<0.05)$ in a given cube were termed directional in that cube. Only those cells that were directional in more than 1 cube were used in the subsequent analyses of directional properties.

The data from each directional cell-cube combination were then subjected to a linear regression in order to calculate the cell's preferred direction vector in that cube (Georgopoulos et al., 1982, 1985; Schwartz et al., 1988; Caminiti et al., 1990). Cell-cube combinations with significant regressions $(p<0.05)$ were considered to be directionally tuned. To determine whether neurons changed their patterns of activity when movements were performed in differing parts of space, a 2-factor (movement direction and movement location) ANOVA was performed, as explained in detail in a previous study (Caminiti et al., 1990). Only cells that were directionally tuned in more than 1 cube were used in the subsequent population analyses. The distributions of preferred direction vectors in the left, center, and right parts of space were represented in 3-D plots.

Subsequent analyses were aimed at determining how the population of preferred direction vectors behaved as movements were made within 


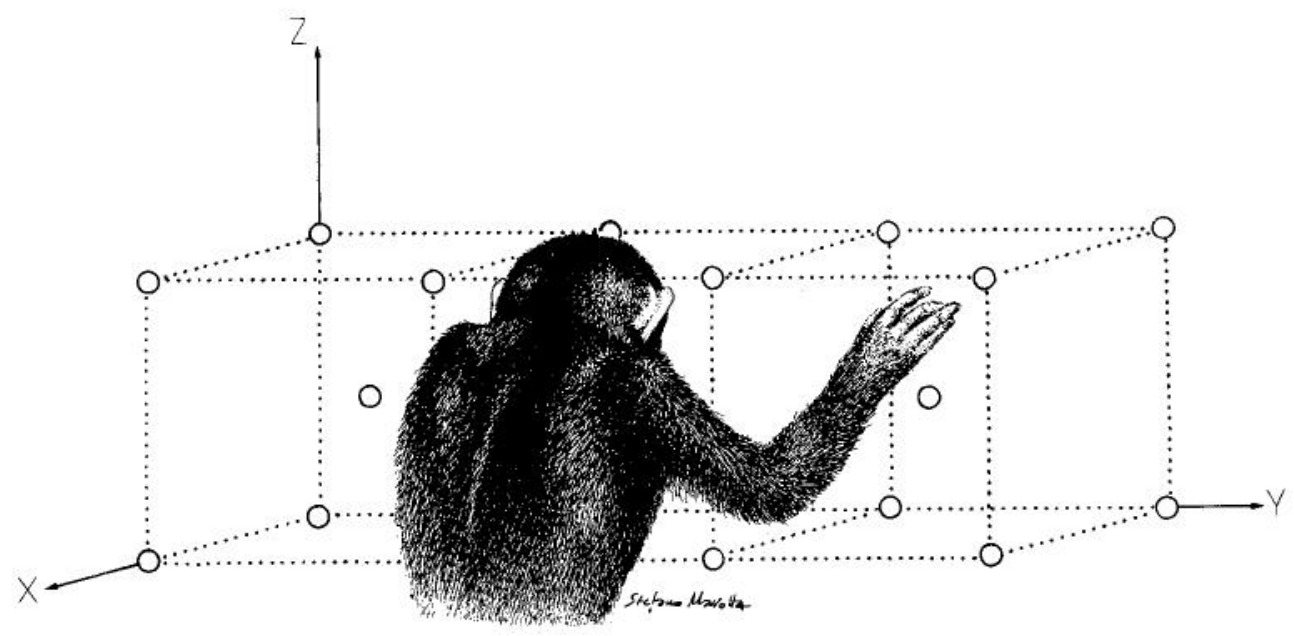

Figure 1. Apparatus and task. Top, layout of the work space in relation to the $\mathrm{X}, \mathrm{Y}$, and $\mathrm{Z}$ coordinates of space and to the animal's body. Push buttons (target lights) are indicated by open circles. The animal was seated on a primate chair, $25 \mathrm{~cm}$ away from the front lights. The center of the center cube was aligned with the body midline at shoulder height. In Task 1 , the animal performed 3 sets of movement directions in the left, center, and right parts of the work space. Black dots indicate the 3 movement origins within each part of space where monkeys made equal-amplitude $(8.7 \mathrm{~cm})$ movements of the same origin in 8 different directions (arrows). Some push buttons are labeled by 2 numbers $(2,11 ; 12,21$; etc.) because they were targets of movements of 2 different origins. Numbers also identify directions of movement. In Task 2 within each part of the work space, the animals performed 3 sets of movements of different directions (arrows) but with common end points. Certain push buttons are labeled by 2 numbers $(32,41 ; 42,51)$ because they were the origin of movement in 2 different directions.
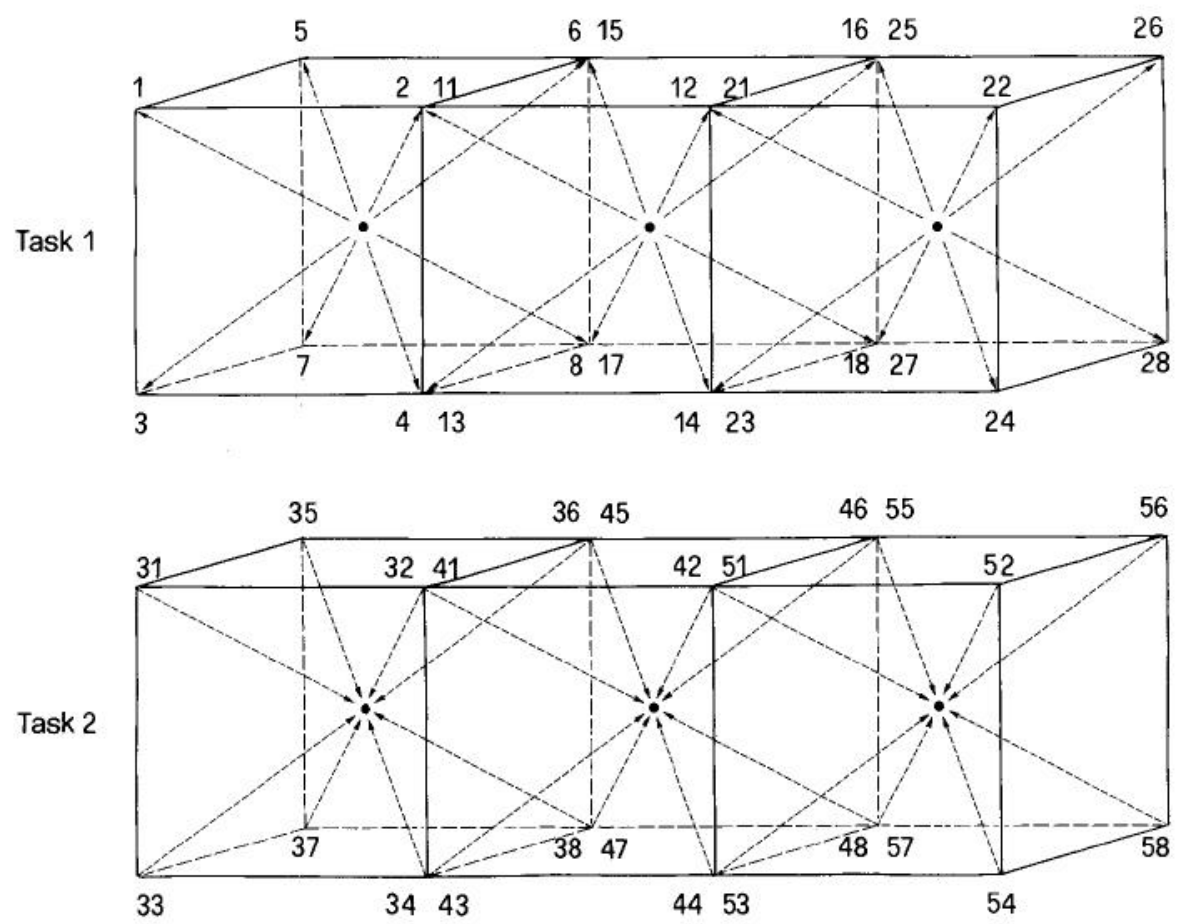

different parts of the work space. The spherical correlation coefficient of Fisher and Lee (1983) was calculated. A positive correlation between 2 paired populations of vectors indicates that there is some rotation that tends to align the 2 populations. Significance levels for the correlation coefficients were calculated using statistical bootstrapping techniques (Efron, 1979).

A significant correlation between 2 populations of vectors permits the calculation of the spherical regression (Jupp and Mardia, 1980). The spherical regression provides a least-squares estimate of the rotation matrix, $\mathbf{R}$, which maximally aligns the 2 populations (see Caminiti et al., 1990). The angles of rotation $\Psi, \Theta$, and $\Phi$ about the $X-, Y-$, and Z-axes (see Fig. 1), respectively, were then computed from the rotation matrix, $\mathbf{R}$, using standard equations of rotation. The positive direction of rotation about the $\mathrm{Z}$-axis was defined as a clockwise rotation when viewed from above. Similarly, positive rotations about the X-and Y-axes were clockwise when viewed from the right of, and behind the animal, respectively. The angles of rotation were calculated such that they represent the rotations necessary to bring the population of vectors from the leftmost region of space into alignment with the vectors of the rightmost region. Confidence intervals for the angles of rotation were calculated using statistical bootstrapping techniques (Efron, 1979). The rotations about the Z-axis of the preferred directions of individual neu- rons were computed by projecting them into the horizontal plane. Within this plane, angular differences between vectors of the different parts of the work space were calculated by simple subtraction (Caminiti et al., 1990).

Analysis of movement population vectors. Population vectors (Georgopoulos et al., 1983, 1986, 1988) were computed for all movement directions in each of the 3 regions of the work space where the animals performed the task. In this analysis we have used weighting function number 2 from Georgopoulos et al. (1988). Spherical correlations (Fisher and Lee, 1983) and spherical regressions (Jupp and Mardia, 1980) were calculated between sets of population vectors from the left, center, and right parts of the work space. These calculations were performed using the same procedures as those used for the preferred direction vectors.

Analysis of movement direction versus end point. The analysis of the changes in discharge frequency of premotor and motor cortical cells with the direction of movement was performed by using an ANOVA on cell firing frequency during the TET in both Tasks 1 and 2 . In Task 1 the presence of a significant variation of cell activity $(F$ test, $p<0.05)$ with the 8 directions of movement in at least 1 of the 3 parts of the work space was considered as an indicator of a relation to the direction of movement. In Task 2 the presence of such a variation was used to 
confirm that a cell was directional, while the lack of significant variation in the ANOVA was considered as an indicator of a relation of cell activity to movement end point. For each cell, this analysis was performed separately for each of the 3 parts of the work space where the animal performed.

Analysis of static positional effects. To assess whether cell activity in both premotor and motor cortices varied with the active holding of the arm in different positions of the extrapersonal space, an ANOVA ( $F$ test, $p<0.05$ ) was performed on cell firing frequency during 2 different epochs of Task 1 and Task 2 . In Task 1 , the ANOVA was performed on cell activity while the monkey was holding his hand immobile on the different peripheral buttons during the THT; in Task 2, the same analysis was performed during the $\mathrm{CT}$, which can be considered as equivalent, from the behavioral point of view, to the THT of Task 1.

Histological data analysis. Histological procedures for 1 of the 2 monkeys were identical to those reported in a previous study (see Caminiti et al., 1990). The other monkey, after the end of recording, was anesthetized with Nembutal $(20 \mathrm{mg} / \mathrm{kg}$; i.p.), the dura was opened, and multiple pressure injections of anatomical tracers were made at known locations with respect to the recording chamber. After a 2-week survival period the animal was deeply anesthetized with Nembutal $(45 \mathrm{mg} / \mathrm{kg}$; i.p.) and transcardially perfused with saline followed by $4 \%$ paraformaldehyde in $0.1 \mathrm{M}$ phosphate buffer $(\mathrm{pH}, 7.4)$. Subsequent to postfixation in the same solution, the brain was photographed and then transferred to a $30 \%$ sucrose solution and allowed to sink. The brain was then cut into $40-\mu \mathrm{m}$ parasagittal sections on a freezing microtome. Sections were mounted and stained with $0.25 \%$ thionine. The sections were then plotted digitally by means of a computer interfaced to potentiometers mounted on a microscope stage. The positions of gliosis and injected material at the injection sites, as well as the locations of giant pyramidal cells, were plotted onto each section. Computer software was then used to align the recording chamber map of penetration sites with the injection sites on the surface of the brain. From this alignment, the locations of penetrations within each section were then reconstructed.

\section{Results}

\section{Trajectories of movement}

The layout of the behavioral apparatus was aimed at obtaining arm movements with similar "parallel" direction but within different parts of the work space. Because the monkeys were free to choose the trajectory between movement origin and end point, recording of movement trajectories was performed to determine whether the hand traveled along approximately parallel paths across the work space. The trajectory records showed that this was indeed the case. A detailed description of movement trajectories in Task 1 can be found in a previous study on motor cortex (Caminiti et al., 1990) and will not be repeated here.

\section{Neurophysiological data base}

This study is based on the quantitative analysis of 156 armrelated cells collected during 63 microelectrode penetrations in the premotor cortex of 2 hemispheres in 2 monkeys. Penetrations were made in a cortical region of proximal limb representation located caudally and medially to the spur of the arcuate sulcus and spanning part of the cortex medial to its medial limb (Fig. 2). The caudalmost of the penetration sites in both animals was $10 \mathrm{~mm}$ rostral to the central sulcus. In spite of the many studies addressing the issue of determining the cytoarchitectonic border between areas 4 and 6 (Sessle and Wiesendanger, 1982; Weinrich and Wise, 1982; Weinrich et al., 1984; Barbas and Pandya, 1987), the precise delineation of such a border remains difficult. Examination of the histological material in this study revealed that, moving rostrally from the crown of the central sulcus, giant pyramidal cell (soma diameter $>29 \mu \mathrm{m}$ ) density decreased gradually and in a variable manner from section to section (see Fig. 2C). Recorded task-related neurons, however, were found to be located in regions of significantly reduced giant
Table 1. Directional composition of the populations of premutor cortical cells studied in the task

\begin{tabular}{lc} 
Cell type & Number \\
\hline Total all cells & $156(100 \%)$ \\
Cells studied in 3 parts of space & $103(66.0 \%)$ \\
Directional & $102(99.0 \%)$ \\
in 3 parts of space & $79(77.4 \%)$ \\
in 2 parts of space & $11(10.8 \%)$ \\
in 1 part of space & $12(11.8 \%)$ \\
Non-directional & $1(1.0 \%)$ \\
Cells studied in 2 parts of space & $38(24.4 \%)$ \\
Directional & $37(97.4 \%)$ \\
in 2 parts of space & $32(86.5 \%)$ \\
in 1 part of space & $5(13.5 \%)$ \\
Non-directional & $1(2.6 \%)$ \\
Cells studied in 1 part of space & $15(9.6 \%)$ \\
Directional & $13(86.7 \%)$ \\
Non-directional & $2(13.3 \%)$ \\
Total directional & $152(97.4 \%)$ \\
\hline
\end{tabular}

pyramidal cell density, when compared with the anterior bank and crown of the central sulcus. Only near the rostral bank of the precentral dimple did the electrode penetrations encroach upon regions of moderate giant cell density. Based upon their locations with respect to sulci and upon the density of giant pyramidal cells, the cortical regions from which task-related neurons were recorded in this study were judged to be coextensive with the premotor cortex (Weinrich and Wisc, 1982; Wcinrich et al., 1984).

Data from the motor cortex used for comparison came from the quantitative study of 207 cells collected in area 4. Of these, 176 were part of a previous study (Caminiti et al., 1990), while the remaining 31 were collected in area 4 of 1 hemisphere of an additional monkey. The results obtained in area 4 while animals performed in Task 1 of the present study have already been published (Caminiti et al., 1990) and will only be cited here for comparison with premotor cortical data. In the premotor cortex, the large majority of neurons $(70 \%)$ studied during the task did not respond to passive somatic stimulation of superficial receptors or to manipulations of deep tissues and/or joints. Those remaining showed varying degrees of modulation under these circumstances. In all cases neuronal modulation was by far more intense during active movement than during passive manipulations.

\section{Directional properties of premotor cortical neurons}

An ANOVA was performed to select those cells that changed their activity significantly ( $F$ test, $p<0.05$; TET epoch) with the direction of movement in 1 or more regions of the work space. Table 1 shows that $152 / 156(97.4 \%)$ neurons were directional and in addition it provides a quantitative evaluation of the capability of these cells to maintain their directionality throughout the work space. As the purpose of this portion of the study was to examine the directional properties of neurons across space, only those cells that were directional in at least 2 parts of the work space were used for subsequent quantitative analyses.

Figure $3 A$ shows the activity of a premotor cortical neuron collected during Task 1. This neuron was directional (ANOVA, 

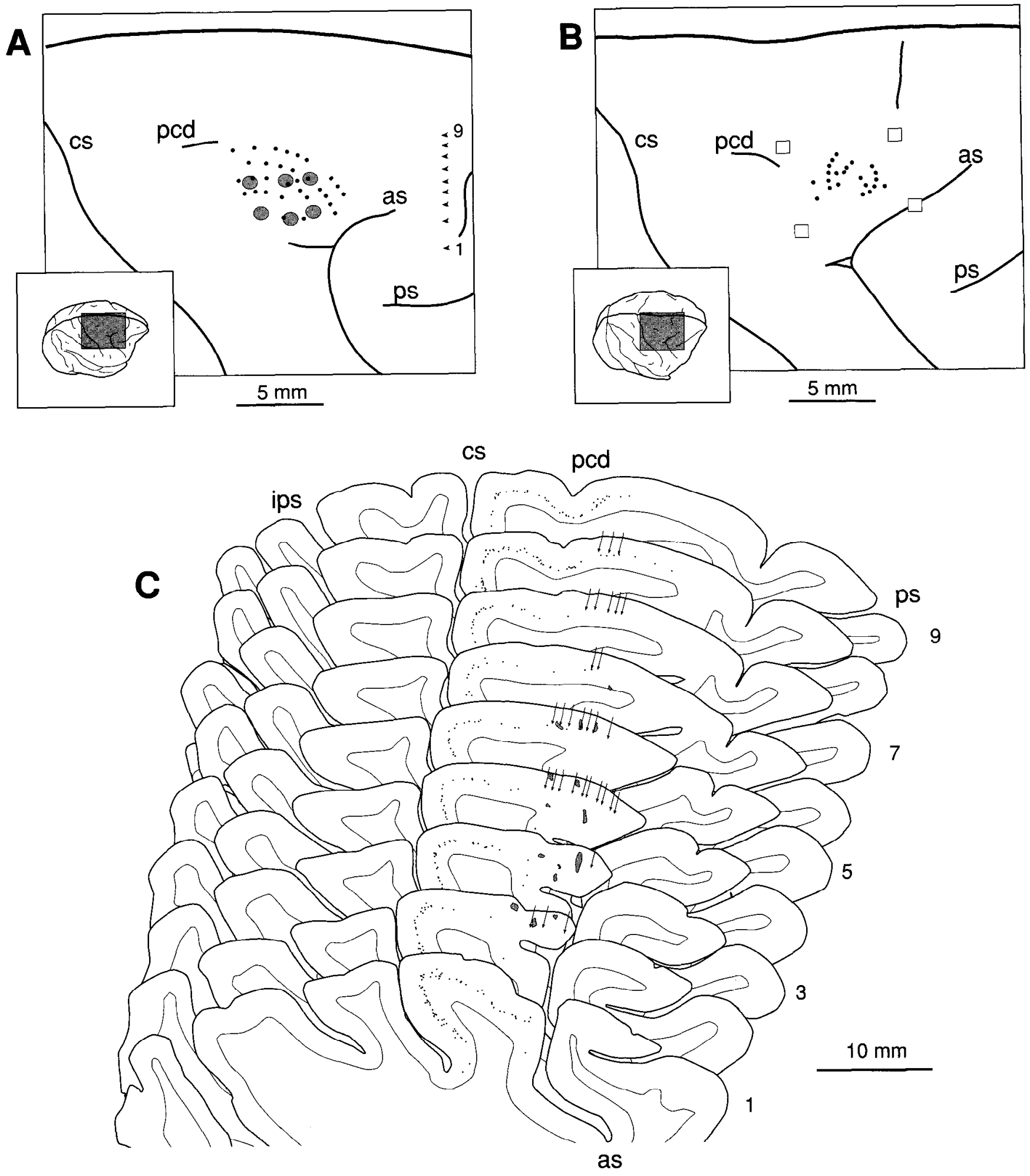

Figure 2. Locations of microelectrode penetrations in the 2 Macaca nemestrina monkeys. A, Surface of right frontal cortex of the first monkey. Small dots indicate entry points of electrode penetrations in which task-related cell activity was recorded. Shaded ovals show the locations of tracer injections at known coordinates. Arrowheads indicate the levels of the parasagittal sections shown in $C$. Shaded area in the inset indicates the region enlarged in the figure. $B$, Surface of the right frontal cortex of the second monkey. Format as in $A$. Open squares correspond to the locations of pins inserted into the cortex at known coordinates. $C$, Series of parasagittal sections from the first monkey. Arrows indicate reconstructed locations of microelectrode penetrations whose entry points are shown in $A$. Small dots represent the locations of giant pyramidal cells ( $>29 \mu \mathrm{m}$ soma size). Shaded areas show the locations of the injected tracer. Numbers beside sections correspond to the arrowheads in $A$. Abbreviations: cs, as, ps, and ips indicate central, arcuate, principal, and intraparietal sulci, respectively; $p c d$ indicates the precentral dimple. 

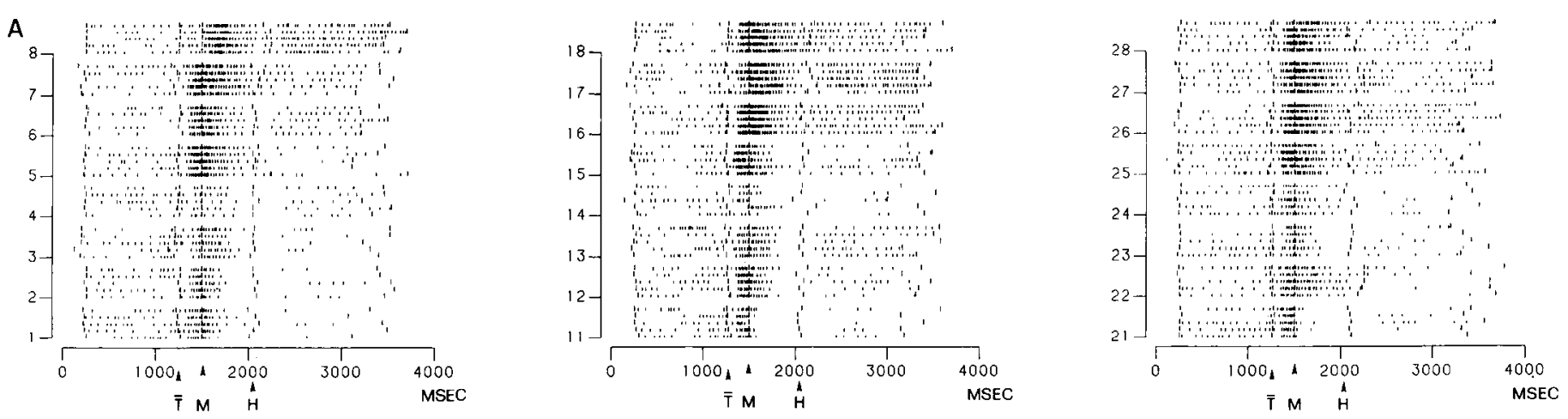

B
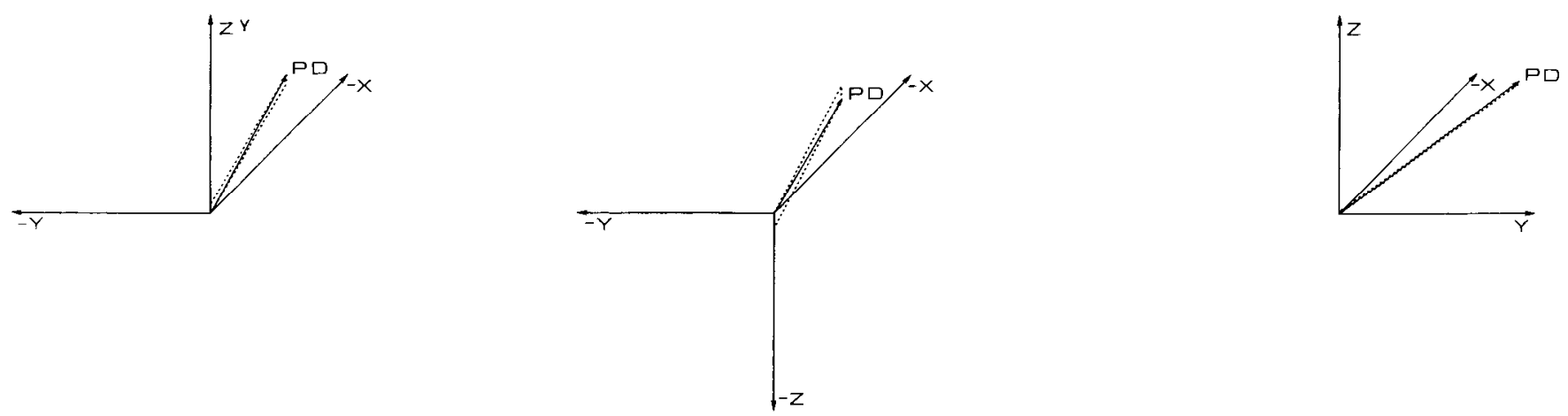

Figure 3. A, Impulse activity of a premotor cortical cell (area 6) recorded during the task. Rasters of 5 replications for every movement direction within the left, center, and right parts of the work space were aligned to the movement onset $(M)$. Target onset is indicated by $T$. Longer vertical bars indicate, from left to right, beginning of the trial, target presentation, movement onset, and beginning $(H)$ and end of target holding time. Numbers on the vertical axes indicate directions of movement as labeled in Figure 1. This cell was directional in all parts of the work space and also changed activity for movements of similar directions performed across the work space. $B$, Spatial orientations of the vectors representing the preferred directions (PDs), in the left, center, and right parts of space, of the cell shown in $A$. PDs are represented within 3 Cartesian coordinate systems centered at the origins of the movements performed in the task. The signs of the X-, Y-, and Z-axes change when necessary to better illustrate the orientation of the PDs. Note the change in the orientation of this cell's PD.

$p<0.05)$ throughout the work space. In addition, the firing frequency of this cell changed in an orderly fashion with changes in movement direction (multiple regression, $F$ test, $p<0.05$ ) in all parts of the work space. Considering all the directional cells tested, such an orderly change (multiple regression, $F$ test, $p<0.05$ ) was observed in $93.2 \%$ of the cell-cube combinations (left, center, and right parts of space considered separately) while, for the remaining $6.8 \%$ of cell-cube combinations, the firing frequency of cells could not be predicted by the regression mod$\mathrm{el}$; therefore, these cell-cube combinations were not further analyzed.

These data indicate that a large majority of the premotor cortical cells studied $(97.4 \%)$ was directional and a large proportion of them ( $93.2 \%$ of cell-cube combinations) was directionally tuned. These results are very similar to those obtained in the motor cortex under the same experimental conditions (Caminiti et al., 1990).

Figure $3 A$ also shows that movements of similar directions performed within different parts of space resulted in changes of firing frequency of this cell. For many triplets of movement directions (1-11-21; 4-14-24; 8-18-28), the frequency and time course of activity and/or the temporal relations to movement onset $(3-13-23 ; 4-14-24 ; 8-18-28)$ changed notably. To determine the number of cells showing similar changes in activity, a 2-factor ANOVA was performed on the firing rate of all cells that were directional in all 3 parts of the work space. Of 78 cells studied, $77(98.7 \%)$ showed significant changes (interaction term, $p<0.05$ ). This is very similar to what was observed in the motor cortex (Caminiti et al., 1990). It follows that changes in firing frequency observed when movements of similar directions were performed across space could result in a change of the cell's preferred direction. This is shown in Figure $3 B$, which illustrates the spatial shift of the preferred direction of the cell shown in Figure $3 \mathrm{~A}$. The preferred direction of this cell undergoes an orderly shift as the animal works in the left, center, and right parts of the work space. Similar changes in the spatial orientations of the preferred direction vectors were observed, though with varying magnitudes, for most cells. This is shown in Figure 4 for the preferred directions of 4 premotor cortical neurons. Due to this cell-to-cell variability, it was deemed necessary to undertake a population analysis of cell preferred directions to assess whether an overall orderly change in their orientations was detectable under the conditions of the task.

\section{The spatial orientation of premotor cortical cell preferred} directions across the work space

This analysis was pcrformed in 4 stcps. First, the spatial distribution of cell preferred directions was examined in each part 


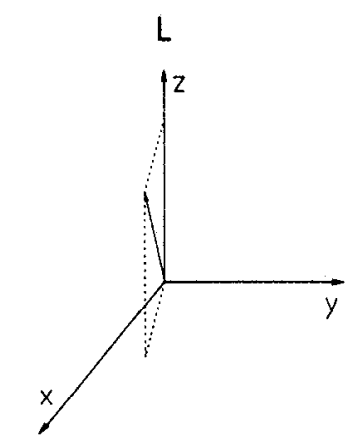

C
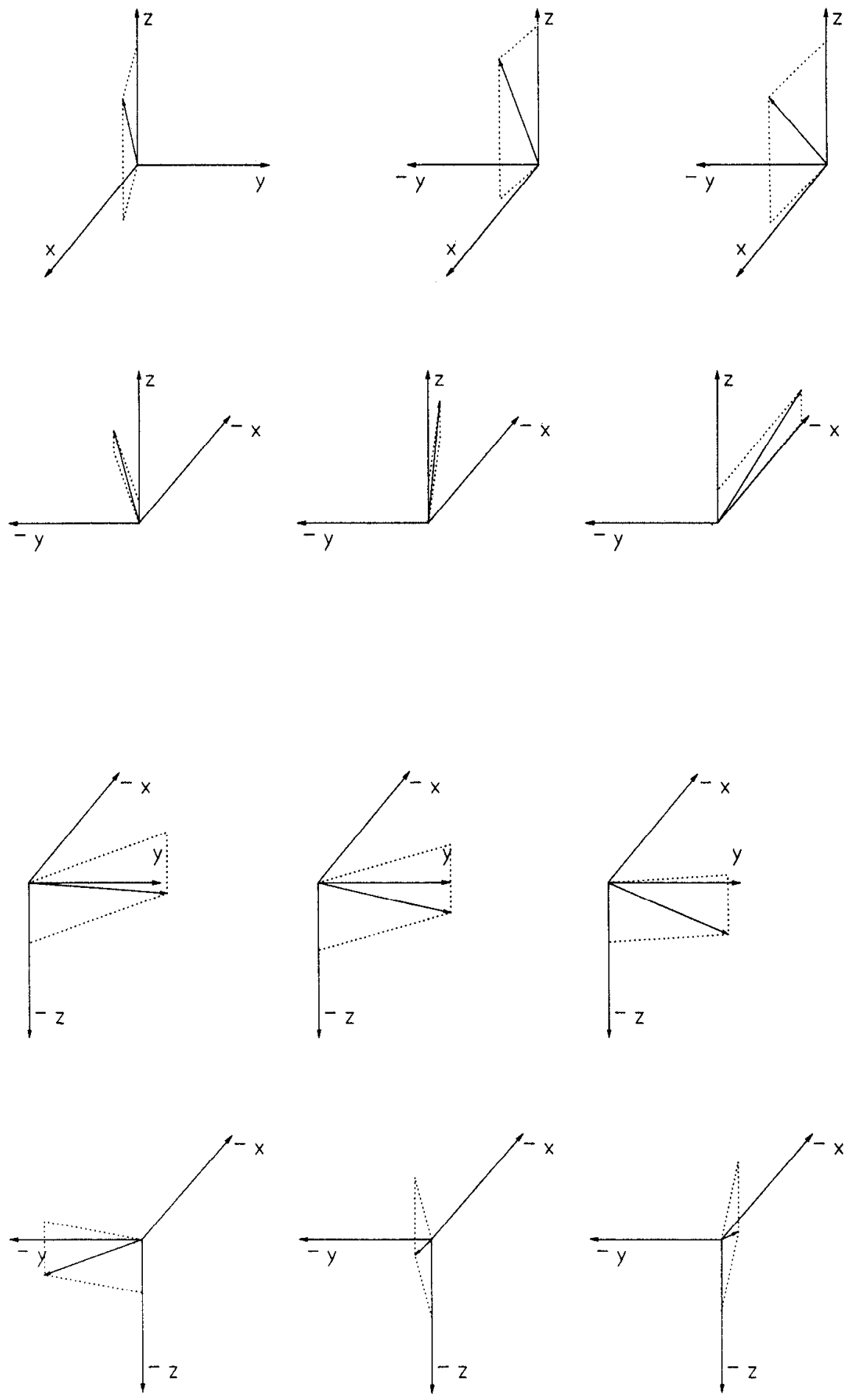

Figure 4. PDs in the left $(L)$, center $(C)$, and right $(R)$ parts of the work space of 4 different premotor cortical cells. Note that for all of these cells the PDs changed orientation as movement of similar directions were made across space; this change had different magnitude for different cells. Conventions as in Figure $3 B$. of the work space. Preferred directions, expressed as vectors of unit length with origin at the origins of movement, covered the entire directional continuum in a uniform fashion throughout the work space (Fig. 5). Second, a study of the degree of correlation between the spatial orientations of preferred directions in the left, center, and right parts of space was performed. For this analysis the spherical correlation coefficient of Fisher and Lee (1983) was used. The results show the existence of a sig- nificant correlation $(p<0.002)$ between the left-center $(r=$ $0.285)$, center-right $(r=0.519)$, and left-right $(r=0.136)$ spatial orientations of cell preferred direction. Third, the spherical regression analysis was performed (see Materials and Methods). The results of this analysis are shown in Table 2 . In the premotor cortex, the amount of rotation necessary to bring into coincidence preferred directions from one to another part of space was minimal around the $\mathrm{X}$ - and $\mathrm{Y}$-axes, indicating that no 

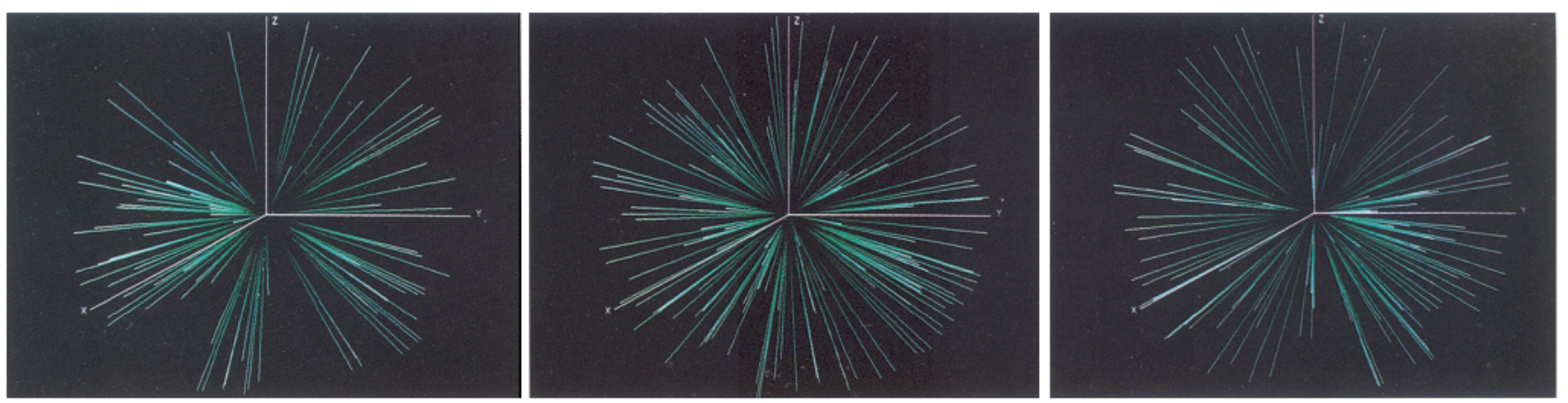

Figure 5. Three-dimensional plots of the distributions of the spatial orientations of cells' PDs obtained as the animals performed in the left, center, and right parts of the work space.

significant changes of spatial orientation of the vectors occurred around these axes. Around the Z-axis (i.e., in the horizontal plane) significantly higher rotations were necessary to bring into coincidence the preferred directions from left to center $\left(17.2^{\circ}\right)$, center to right $\left(17.6^{\circ}\right)$, and left to right $\left(42.0^{\circ}\right)$ parts of space. In the premotor cortex, $95 \%$ confidence intervals (CIs) for rotations in the horizontal plane were $\left[10.6^{\circ}, 21.8^{\circ}\right]$ and $\left[14.0^{\circ}, 21.7^{\circ}\right]$ for regressions between left-center and center-right, and $\left[34.2^{\circ}, 47.9^{\circ}\right]$ for regression between left-right parts of space. Data from the motor cortex were very similar. The rotations of premotor cortical cells' preferred directions are shown in Figure 6. It can be seen that these shifts were different for different cells. However, at the population level, these shifts resulted in an overall rotation occurring mainly in the horizontal plane.

Finally, to substantiate further the results of the spherical regression, angular differences in the horizontal plane (around the Z-axis) between preferred directions of individual cells in the 3 parts of the work space were computed and represented in the form of frequency distributions (Fig. 7). The results obtained were consistent with the spherical regression analysis. In the premotor cortex, the median angular difference was maximal in the horizontal plane (Fig. 7) and was $19^{\circ}$ between preferred directions lying in adjacent parts of space and $43^{\circ}$ between preferred direction from the nonadjacent left-right parts of space. In the motor cortex, corresponding values of median angular differences were very similar (Caminiti et al., 1990). In both cortices the differences between the orientation of cell preferred directions show a common trend, though they are slightly smaller in the motor than in the premotor cortex.

As a result of the side-by-side horizontal arrangement of the 3 parts of the work space, in order to make arm movements of similar direction within different parts of space, the animals had first to bring the arm from one part of the work space to another. This caused a rotation of the shoulder joint mainly in the horizontal plane (around the Z-axis). Measurements of shoulder joint angles showed that horizontal rotations of approximately $20^{\circ}$ and $18^{\circ}$ were necessary to bring the arm from the left to the center and from there to the right part of the work space, respectively. These values were consistent across animals, in spite of small individual differences due to arm length and shoulder width. We conclude that the horizontal rotation of the population of premotor and motor cortical cell preferred directions parallels a similar rotation of the shoulder joint, the one imposed by the behavioral condition of the task.

An additional question is whether the shift of preferred directions in the horizontal plane observed during the time from target presentation to the end of movement was present both before the onset of movement (i.e., during RT) and during the execution of the movement (during MT). The spherical regression analysis showed that the angles of rotation had similar magnitudes during the reaction time and the movement time in both premotor and motor cortices.

\section{The neuronal movement population vector}

The broad relationship between cell activity and direction of movement has led to the concept that direction of movement is encoded by a neural population and that neuronal population vectors (Georgopoulos, 1983, 1986, 1988) can be used to represent this code. The population vector is a sum of vectorial contributions made by individual neurons in the direction of their preferred directions. In many previous studies of various brain regions (see Georgopoulos et al., 1988, for a review) the neuronal population vector has proven to be a good predictor of movement direction. In the present study, population vectors were computed for the neuronal populations from both the premotor and motor cortices. In the premotor cortex the average angular differences between the population and movement vectors were $15.7^{\circ}, 11.4^{\circ}$, and $16.2^{\circ}$ in the left, center, and right parts of the work space, respectively. Similar values were obtained from the motor cortex (Caminiti et al., 1990). To determine any consistent shift in the orientation of the population vectors across space, the spherical correlation and spherical regression were calculated as for the populations of cell preferred directions. In the premotor cortex, the spherical correlation coefficients between neuronal movement population vectors from left and center, and center and right parts of the work space were 0.915 and 0.970 , respectively. The correlation coefficient between population vectors from left and right parts of the work

\begin{tabular}{|c|c|c|c|}
\hline & $\Phi$ & $\Theta$ & $\Psi$ \\
\hline left-center & $17.2^{\circ}$ & $0.4^{\circ}$ & $3.2^{\circ}$ \\
\hline center-right & $17.6^{\circ}$ & $-3.3^{\circ}$ & $-1.1^{\circ}$ \\
\hline left-right & $42.0^{\circ}$ & $-2.2^{\circ}$ & $0.0^{\circ}$ \\
\hline
\end{tabular}

$\Phi=$ rotation around $Z$-axis.

$\Theta=$ rotation around $\mathrm{Y}$-axis.

$\Psi=$ rotation around $\mathrm{X}$-axis 

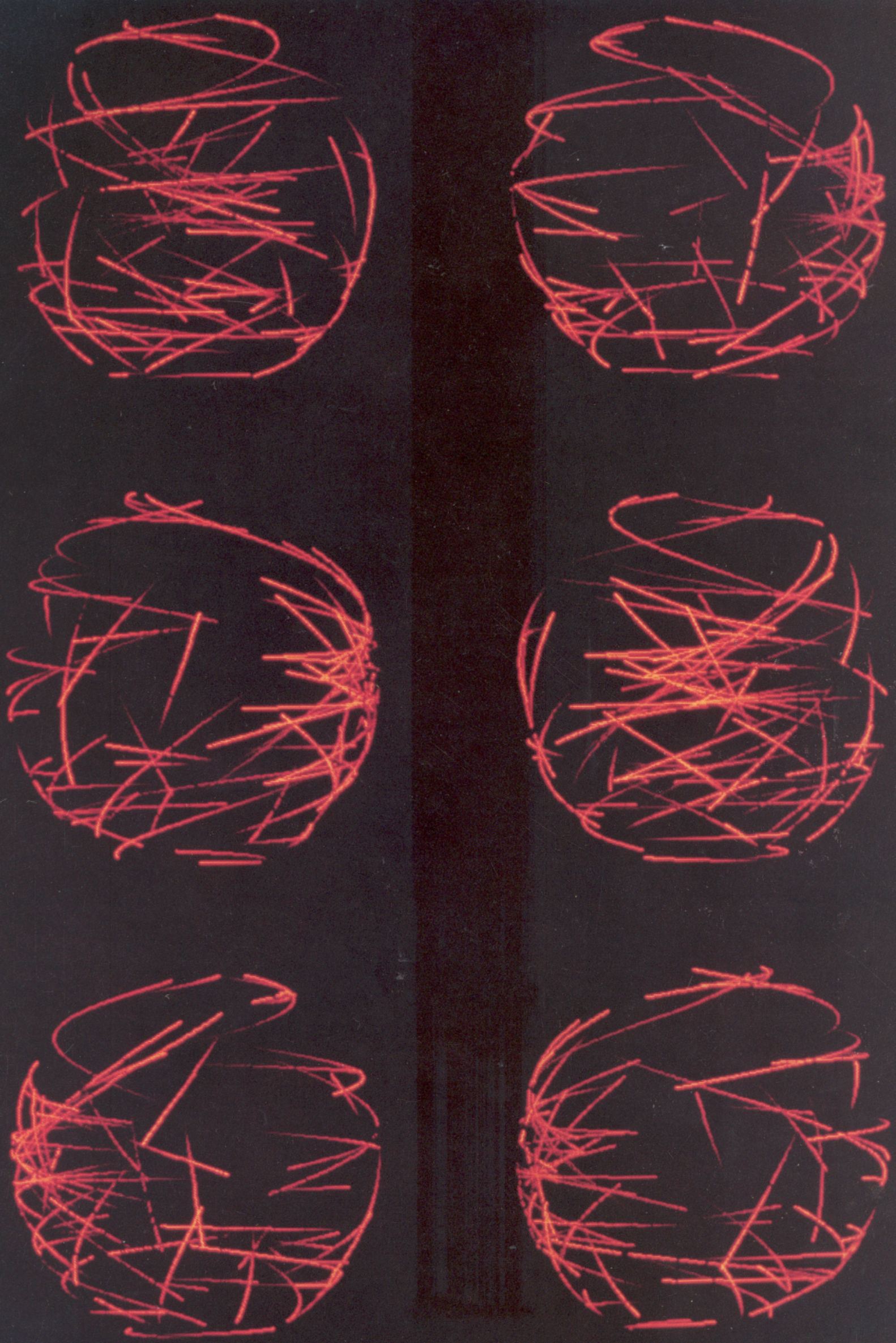

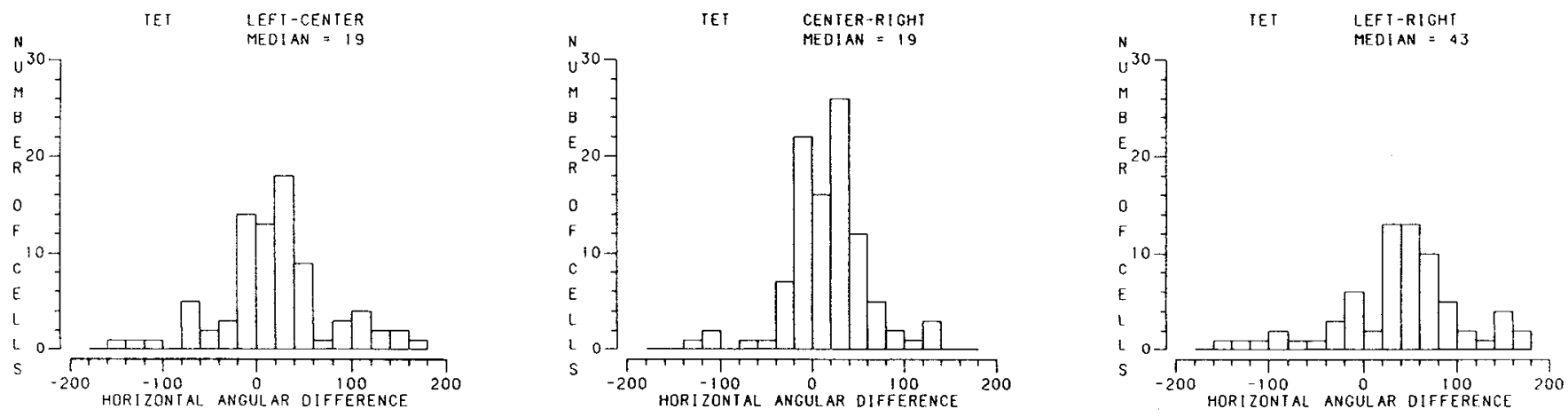

Figure 7. Frequency distribution of the angular difference between the spatial orientation of premotor cortical cell preferred directions across the work space. These differences were computed between PDs lying in the left and center, center and right, and left and right parts of the work space. $T E T=$ total experimental time.

space was 0.836 . In the motor cortex, corresponding values were $0.986,0.971$, and 0.946 , respectively. Thus, in both cortices, the spatial orientations of the population vectors are highly correlated across space. More interestingly, the spherical regression (Table 3 ) shows that in both frontal areas there were no significant rotations of the population vectors as the animal performed within different parts of space. The angles of rotation of the population vectors are all very small, independent of the spatial axis considered. The lack of any significant rotation of the neuronal movement population vectors in both premotor and motor cortices, when movements of similar direction were performed across space, is shown in Figure 8, where movement population vectors from different parallel movement direction were represented as "collapsed" to a single region of the work space to facilitate the comparison of their orientation.

\section{Movement direction versus movement end point}

In Task 1, movement direction and movement end point were confounded since the movements in different directions were also toward different end points. To dissociate these 2 variables we studied cell activity when animals made movements with differing origins and directions but converging to a common end point, as was the case in Task 2 (Fig. 1). Within each of the 3 parts of the work space, monkeys made arm movements in 8 different directions, from 8 different origins but having a common end point. Figures 9 and 10 show the activity of a premotor and of a motor cortical cell, respectively, studied during Tasks 1 and 2. Both cells were directional (ANOVA, $F$ test, $p<0.05$ ) in both tasks, suggesting that their activity relates to the movement direction and not to movement end point. In Task 2 we tested 37 premotor and 29 motor cortical cells that had also becn studicd in Task 1 . The results showed that in the premotor cortex, when cells were studied in only a single part of space, $4 / 18(22.2 \%)$ were directional in both tasks, leaving open the possibility that the remaining $77.8 \%$ of cells might be related to either movement direction or end point. However, when premotor cells were studied within a larger region of the work space, that is, in 2 or 3 cubes, the percentage of cells directional in some part of space in both tasks increased to $100 \%$ and to $83.3 \%$, respectively. This indicates that, in at least some part of the extrapersonal space, their activity was not related to the end point but to the direction of movement, thus pointing out the importance of spatial factors in determining cell properties in this area.

In the motor cortex, $4 / 9(44.4 \%)$ cells studied in a single part of space were directional in both Tasks 1 and 2, while $100 \%$ of those cells that could be studied throughout the entire work space displayed directionality in some part of space in both tasks. Here, as well as in the premotor cortex, spatial factors seem to play a crucial role in shaping cell properties and movement direction represents a much stronger signal than movement end point in influencing cell activity.

\section{Changes in cell activity with active holding at different positions in 3-D space}

Previous studies (Caminiti et al., 1981; Georgopoulos et al., 1984) have shown that when a monkey holds its hand at various positions in a 2-D space, cell activity in motor cortex and area 5 varies in a linear fashion with the position of the hand in space. These positional gradients have recently been described also in the motor cortex using a 3-D task (Kettner et al., 1988) but have not yet been analyzed in the premotor cortex. We studied cell activity in these areas while monkeys were actively holding their hand at the vertices of the 3 imaginary cubes that delimited the work space (Fig. 1). In each cube the hand occupied 8 different positions. Because the 3 cubes were adjacent in the horizontal plane, 8 different positions $(2-11,12-21,4-13$, $14-23,6-15,16-25,8-17,18-28)$ were common to 2 cubcs. Therefore, the absolute number of spatial loci tested was 16 . This analysis was performed in 2 ways. First an ANOVA was performed to determine the number of cells that showed a significant ( $F$ test, $p<0.05$ ) change of steady-state frequency of

\section{$\leftarrow$}

Figure 6. Three-dimensional plots showing the rotation of the spatial orientation of premotor cortical cell preferred directions as movements of similar directions were made within different parts of space. Each red line represents the trajectory followed by the preferred direction vector of an individual motor cortical neuron, with the tail (darkest part) indicating the original position of the vector in the left part of the animal's work space and the head (brightest part), its position in the right part of space. Rotations are viewed from 6 different angles: $0^{\circ}$ (top left), $60^{\circ}($ top right), $120^{\circ}$ (center left), $180^{\circ}$ (center right), $240^{\circ}$ (bottom left), $300^{\circ}$ (bottom right). In each plot brighter vectors indicate preferred directions lying in the portion of sphere nearest to the observer. In the $0^{\circ}$ view, the observer's perspective coincides with that of the monkey performing the task. 

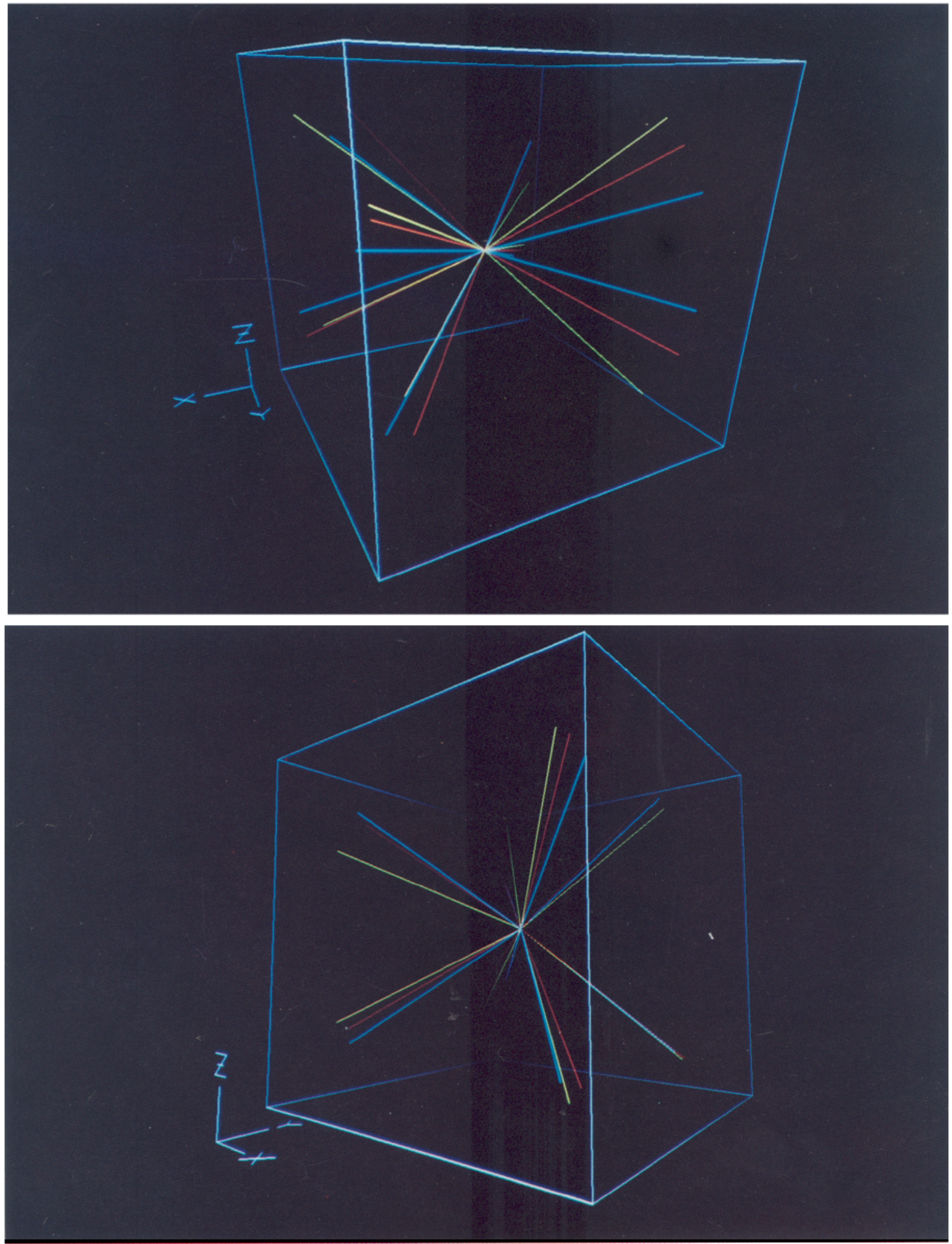

Figure 8. A, Neuronal movement population vectors calculated from cell activity in the premotor cortex during the performance of Task 1. Colored vectors represent population vectors from the 3 regions of the work space (yellow from left, red from center, and blue from right cubes). Vectors from across the work space have been "collapsed" to a single cube and normalized to unit length in order to facilitate comparisons between population vectors of "parallel" movements. Thus, for example, the 3 vectors pointing to the upper right represent the population vectors for movement directions 6 (yellow), 16 (red), and 26 (blue). The axes correspond to the $\mathrm{X}, \mathrm{Y}$, and Z coordinate axes of Figure 1 . Note how for this as well as for the remaining triplets of parallel movement directions, the spatial orientation of neuronal population vectors did not change notably. $B$. Neuronal population vectors calculated from activity in the motor cortex during the performance of Task 1 . Conventions and symbols as in Figure $8 \mathrm{~A}$. Note how in the motor cortex the spatial orientation of the movement population vectors remains similar for the various triplets of parallel movement directions. 
Task 1
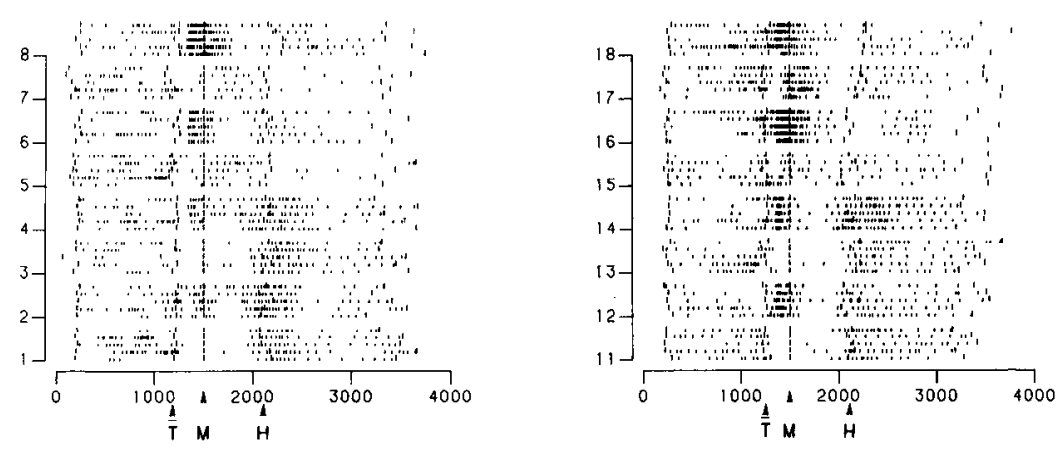

Task 2

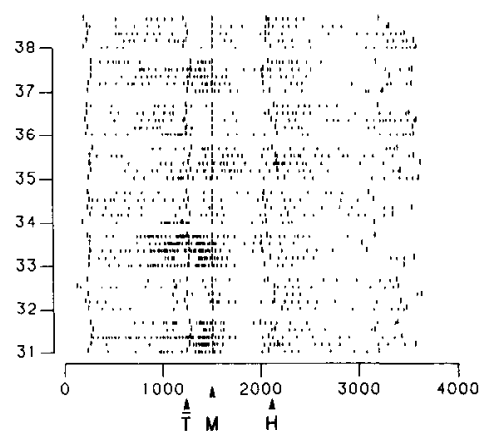

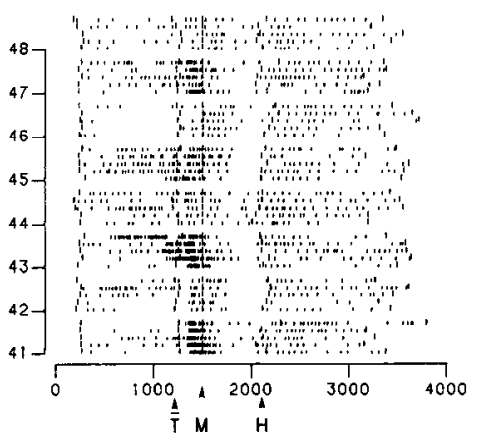
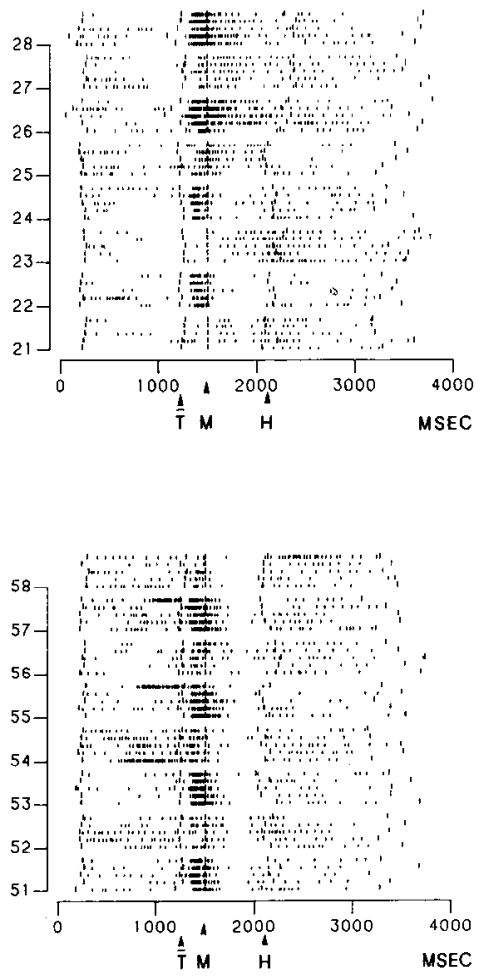

Figure 9. Impulse activity of a premotor (area 6) cortical cell recorded during Task 1 and Task 2 . This cell was directional in both tasks. Conventions and symbols as in Figure $3 A$.

discharge during the THT of Task 1, as the hand occupied different positions in space. This analysis was performed separately for each of the 3 parts of the work space. Table 4 shows that in the premotor cortex, $138 / 156(88.5 \%)$ cells tested showed significant static spatial effects and, therefore, were labeled as positional. These positional effects on cell activity can be clearly seen during the THT for the premotor cortical cells shown in Figure $3 A$ and in Figure 9 (Task 1 ) and for the motor cortical cell shown in Figure 10 (Task 1 ). These effects were generally present throughout the work space and the probability of detecting them increased with the size of the spatial region where these cells were tested. In fact, $103 / 110(93.6 \%)$ of the cells studied in 3 parts of space were positional. This percentage decreased to $83.3 \%$ for those cells that could be studied in 2 parts of space, and dropped to $62.5 \%$ for the cells tested in only 1 part of space. Qualitatively and quantitatively similar results

Table 3. Spherical regression analysis on movement population vectors: comparison between premotor $(P)$ and motor $(M)$ cortices

\begin{tabular}{llrrr} 
& & \multicolumn{1}{c}{$\Phi$} & $\Theta$ & \multicolumn{1}{l}{$\Psi$} \\
\hline left-center & $\mathrm{P}$ & $0.5^{\circ}$ & $0.0^{\circ}$ & $-2.0^{\circ}$ \\
& $\mathrm{M}$ & $1.8^{\circ}$ & $-0.2^{\circ}$ & $0.1^{\circ}$ \\
center-right & $\mathrm{P}$ & $-0.1^{\circ}$ & $-0.2^{\circ}$ & $0.1^{\circ}$ \\
& $\mathrm{M}$ & $0.7^{\circ}$ & $-1.5^{\circ}$ & $-0.5^{\circ}$ \\
left-right & $\mathrm{P}$ & $0.6^{\circ}$ & $-2.2^{\circ}$ & $0.3^{\circ}$ \\
& $\mathrm{M}$ & $-0.1^{\circ}$ & $-1.2^{\circ}$ & $-1.0^{\circ}$ \\
\hline
\end{tabular}

$\Phi=$ rotation around $\mathrm{Z}$-axis.

$\theta=$ rotation around $Y$-axis.

$\Psi=$ rotation around $X$-axis. were obtained in the motor cortex (Table 4), similar to what was observed by Kettner et al. (1988). This suggests that if all cells could have been studied throughout the entire work space, the percentage of positional ones probably would have been higher than that shown in Table 4.

Since these results were obtained from cell activity studied during the holding phases following different movements, there is the possibility that the effects observed were in part carryover effects from the preceding movements. To exclude this

\begin{tabular}{|c|c|c|}
\hline & Premotor & Motor \\
\hline Total number of cells & $156(100 \%)$ & $207(100 \%)$ \\
\hline Cells studied in 3 parts of space & $110(70.5 \%)$ & $171(82.6 \%)$ \\
\hline Positional & $103(93.6 \%)$ & $160(93.5 \%)$ \\
\hline in 3 parts of space & $55(53.4 \%)$ & $106(66.2 \%)$ \\
\hline in 2 parts of space & $32(31.1 \%)$ & $36(22.5 \%)$ \\
\hline in 1 part of space & $16(15.5 \%)$ & $18(11.2 \%)$ \\
\hline Nonpositional & $7(6.4 \%)$ & $11(6.4 \%)$ \\
\hline Cells studied in 2 parts of space & $30(19.2 \%)$ & $31(15.0 \%)$ \\
\hline Positional & $25(83.3 \%)$ & $28(90.3 \%)$ \\
\hline in 2 parts of space & $19(76.0 \%)$ & $19(67.9 \%)$ \\
\hline in 1 part of space & $6(24.0 \%)$ & $9(32.1 \%)$ \\
\hline Nonpositional & $5(16.6 \%)$ & $3(9.7 \%)$ \\
\hline Cells studied in 1 part of space & $16(10.2 \%)$ & $5(2.4 \%)$ \\
\hline Positional & $10(62.5 \%)$ & $2(40.0 \%)$ \\
\hline Nonpositional & $6(37.5 \%)$ & $3(60.0 \%)$ \\
\hline Total positional & $138(88.5 \%)$ & $190(91.8 \%)$ \\
\hline
\end{tabular}


Task 1
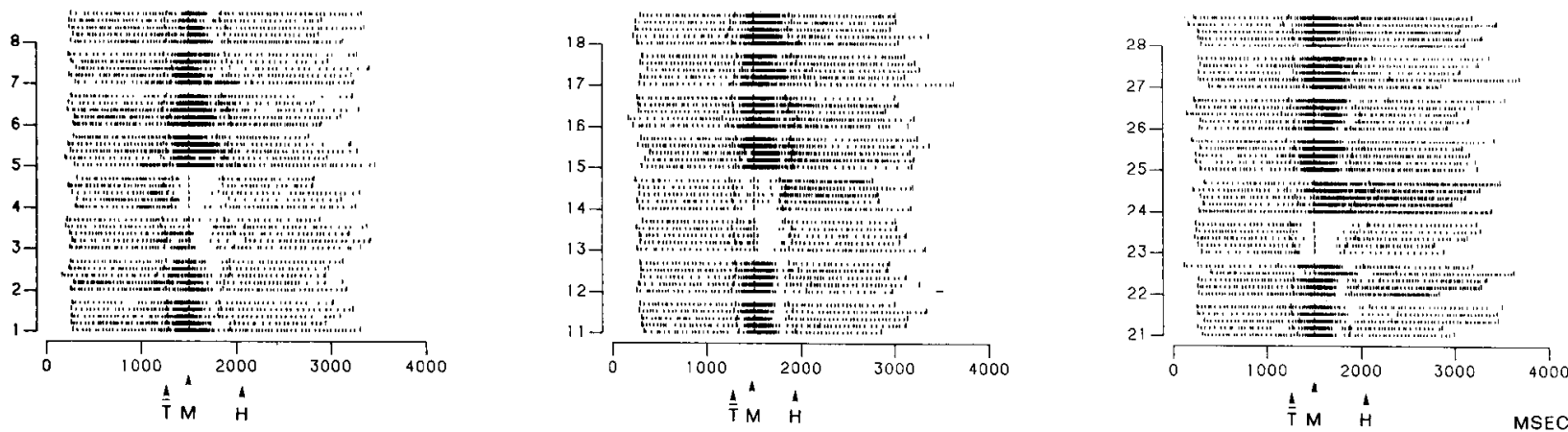

Task 2
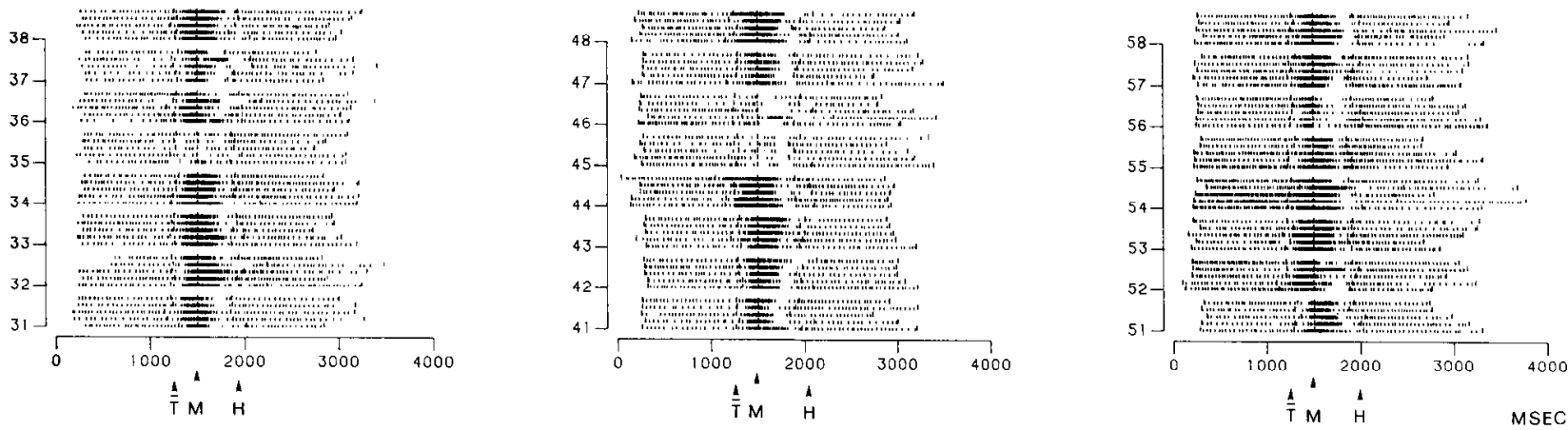

Figure 10. Impulse activity of a motor (area 4) cortical cell recorded during Task 1 and Task 2 . This cell was directional in both tasks. Conventions and symbols as in Figure $3 A$.

possibility, the same analysis was repeated by studying cell activity during the control time of Task 2 , when the hand was actively positioned in different points in space at the beginning of the behavioral trial (Fig. 9, Task 2 and Fig. 10, Task 2). During Task 2 the percent of cells that could be studied throughout the entire work space and showing static spatial effects was $75.0 \%$ in premotor and $88.2 \%$ in motor cortex. This is very similar to that which was observed during Task 1 where these percentages were $88.5 \%$ and $91.8 \%$, respectively.

These results indicate that in both premotor and motor cortices cell activity varies with the position occupied by the hand in space. Because each hand position was achieved by different combinations of angles at the shoulder and/or at the elbow joint, it can be concluded that a signal concerning the spatial position and oricntation of the arm is present at the premotor and motor cortical levels.

\section{Discussion}

The aim of this study was to analyze the coordinate system used by the premotor cortex for representing arm movements to visual targets in 3-D space, and to compare it, in this respect, with the motor cortex. There are 3 main points to be discussed in this paper. First, the activity of premotor cortical neurons is broadly tuned around a preferred direction of movement. Second, the orientations of these preferred directions rotate with the arm in space, providing cues for interpreting the transformation from extrinsic to intrinsic coordinates performed by the frontal cortex. Third, neuronal movement population vectors in both premotor and motor cortices continue to signal movement direction accurately in the presence of these shifts of in- dividual cell preferred directions. In addition, the hypothesis of coding of movement direction versus movement end point in premotor and motor cortices will be discussed.

\section{Relations of premotor cortical cell activity with direction of movement in 3-D space}

Our analysis was restricted to neurons related to arm movements at the shoulder and/or at the elbow joints for the reason that movements about these joints carry the hand along a desired path in space. The existence of neurons related to proximal joint movements in the dorsal part of premotor cortex is not new (Weinrich and Wise, 1982; Kurata and Tanji, 1986; see Brinkman and Porter, 1983, and Wise, 1985, for a review) and their directionality has also been described (Weinrich and Wise, 1982; Weinrich et al., 1984) as well as the directionality of the premotor neurons related to distal movements (Kubota and Hamada, 1978). These studies, however, did not provide a detailed description of the directional relations of premotor cortical cells because they were aimed at different questions. In our study, neurons showing significant variations in activity with movement direction made up the large majority $(97.4 \%)$ of premotor neurons, similar to what was observed in the motor cortex (see also Schwartz et al., 1988; Caminiti et al., 1990). The relations of cell activity with movement direction were described by a tuning function for which cell activity was maximal in a given direction of movement and decreased in an orderly fashion with movement directions farther and farther away from the preferred one. These directional properties are very similar to those of motor cortical neurons. In both areas they can be described through the same model and suggest the conclusion that in both 
cortices the treatment of directional information is based on common principles.

\section{The directional properties of premotor cortical cells when movements of similar direction were performed within different parts of space}

An objective of this study was to determine whether and to what extent the spatial orientation of premotor cortical cell preferred directions changed when movements of similar "parallel" directions were performed within different parts of space. The experimental data clearly showed a significant shift in the spatial orientation of cell preferred directions. This shift had different magnitudes for different cells, but at the population level had a clear spatial order, occurring mainly around the vertical axis and, therefore, in the horizontal plane. Moreover, the magnitude of this shift was very similar to the rotation of the shoulder joint necessary to bring the arm into the 3 horizontally adjacent parts of space where the animals performed the task. This modification of the spatial orientation of cell preferred direction was already present and with similar magnitude during the reaction time, suggesting that it might reflect a central process exhibiting congruence between planning and execution of movement. Finally, the rotation of premotor cells' preferred directions was qualitatively and quantitatively similar to that observed in the motor cortex, suggesting that both of these frontal cortical areas contain an internal representation of space where coding of movement direction occurs within a coordinate system centered on the shoulder joint.

The subtle differences observed between these cortical areas, the higher correlations and the smaller rotations across the work space of motor as compared to premotor cortical cells' preferred directions, could, however, be physiologically relevant. They seem to suggest a more remote link of premotor cortical cell activity with the "needs" of the peripheral motor apparatus. It is difficult to resist the conclusion that these subtle differences, though not substantiated on quantitative grounds, indicate that in the central representation of any process where a sensorimotor transformation of coordinates is required, the more one approaches the cortical areas closer to the peripheral motor apparatus, the more the relevant information is transformed to the coordinates that are proper for the effectors.

These data can be used as a basis for interpreting coordinate transformations in the frontal cortex. When we make arm movements to a visual target in space, sensory information concerning the spatial location of the target must be transformed into an appropriate motor command. Recent behavioral studies on human subjects (Soechting and Flanders, 1989a) have suggested that the visual system provides an accurate representation of the target location in space and that once the spatial location of the target is represented in an intrinsic body-centered frame of reference, motor commands that move the arm toward the target can be generated by mapping the target location into an appropriate level of muscle activity for which knowledge of the initial orientation of the arm is essential (Soechting and Flanders, 1989b).

Our experimental data showed how in both motor and premotor cortices the spatial orientation of cell preferred directions shifted to "follow" the changes in orientation of the arm in space. These data are consistent with the hypothesis that premotor and motor cortical cells command muscle synergies, which can be represented by a vector (the cell's preferred direction) corresponding to the global effect of the motor command on the position of the arm. Because for both shoulder and elbow joints the vectorial effects of a cortical command addressed to the muscles will tend to be more constant in an arm-centered coordinate system than in an external reference frame, the orientation of the cell's preferred direction will be more invariant in an arm-centered reference frame. We hypothesize (see also Caminiti et al., 1990) that the interaction of visually derived information concerning the direction of movement, with a proprioceptive one relative to the position of the arm in space, detcrmincs the rotation of the spatial oricntation of premotor and motor cortical cell preferred directions. It is possible to show (Y. Burnod, P.B. Johnson, and R. Caminiti, in preparation) that a bilinear combination of these 2 sensory inputs provides an appropriate computation of the motor command in an arm-centered reference frame, when the visual information on the target is given in a body-centered reference frame. Furthermore, this bilinear combination can simply be learned with the spontaneous movements of the arm. Our data do not show where, within the distributed motor system, this combination of inputs occurs and which are the processing steps. For instance, more elementary combinations between visual and somatic inputs could first be performed in the parietal lobe, with properties similar to those of neurons combining visual inputs in retinal coordinates and eye position in the orbit (Andersen and Mountcastle, 1983; Andersen et al., 1985; Andersen and Zipser, 1988) to provide a code in craniotopic spacc. The premotor cortex could represent a critical processing step for the appropriate coordinate transformation because it receives both visuospatial (Kubota and Hamada, 1978; Godschalk et al., 1981; Rizzolatti et al., 1981b; Weinrich and Wise, 1982; Weinrich et al., 1984; Godschalk et al., 1985; Kurata and Tanji, 1986; Okano and Tanji, 1987; Riehle and Requin, 1989) and somatic (Rizzolatti et al., 1981a; Kurata and Tanji, 1986; Hummelsheim et al., 1988 ) information. The results of the present study, by showing a significant variation of cell activity as the hand occupies different positions within the 3-D space, indicate that a signal concerning the orientation of the arm in space influences both premotor and motor cortical activity. The similarity of these mechanisms in premotor and motor cortices may facilitate the transformation of directional information between these frontal cortical fields allowing the motor cortex with its privileged access to the peripheral motor apparatus to select and activate those weighted combinations of muscles (see Georgopoulos et al., 1982 and Schwartz et al., 1988, for a discussion) which will move the hand in the desired direction of space.

\section{Coding of movement direction in the premotor cortex: a population code}

Premotor cortical cells, similar to motor cortical, parietal (Kalaska et al., 1983), and cerebellar (Fortier et al., 1989) ones, are broadly tuned around their preferred direction. Our ability to move our arms accurately in a given direction despite the coarse tuning of cortical cells implies the existence of a population code. Population codes have in fact been proposed for coding of movement direction in the motor (Georgopoulos et al., 1983, 1985, 1986; Kalaska et al., 1989; Caminiti et al., 1990) and parietal (Kalaska et al., 1983) cortices and in the cerebellum (Fortier et al., 1989). The results obtained in this study indicate that in the premotor cortex as well the coding of movement direction is a function of the population. The experimental design of this study permitted the evaluation of the ability of the neuronal population vector to predict movement direction 
throughout the work space. The directions of movements were similar in the 3 parts of the work space tested and, therefore, to remain good predictors of movement direction across space, the neuronal population vectors should not have changed their orientations. The results of the spherical regression analysis performed on the population vectors were in this respect unequivocal. When the animals performed within different parts of space, despite the significant changes in muscular activity, joint angles, and even orientation of individual cell preferred directions, neuronal movements populations vectors did not change spatial orientation in either premotor or motor cortices.

These results are consistent with the basic notion of a cortical population code for movement direction given that (1) the maximum activity of each neuron corresponds to a preferred direction that changes with the initial orientation of the arm, and (2) in each part of the work space all the cell preferred directions provide a uniform sampling of the 3-D directional continuum. Assuming that the level of activation of an individual neuron is determined by projecting the desired movement direction vector onto the cell's preferred direction vector, any individual neuron will be activated differentially when the animal performs parallel movements within different parts of space. However, because the movement vector is projected simultaneously onto the entire population of preferred direction vectors, and the preferred direction vectors are distributed uniformly in space, the sum of all of these projections (i.e., the population vector) will always have the same orientation as the movement vector.

It, therefore, seems that in all cortical areas of the distributed motor system so far studied and in the cerebellum as well given features are encoded by distributed representations very different from "local" representations (Feldman, 1981) where very few units with their connectivity would provide the basis of a given function. Finally, it is worth mentioning that coding mechanisms based on distributed representations have been described not only in the different regions of the motor system but have been widely used to explain feature extraction in the visual system (Steinmetz et al., 1987; Vogels, 1990; for a discussion, see Sejnowski, 1986).

\section{Coding of movement direction versus movement end point in premotor and motor cortices}

The results of this study show that when the movement direction was dissociated from the movement end point, cell activity in both premotor and motor cortices was related to the trajectory of movement and not to final position in space. Trajectory of movement, here, is intended as a descriptive term, because the assessment of a relation of cell activity with the actual trajectory performed by the hand in space would require repetitions of the same trajectory under a variety of limb configurations and this was not attempted in this study. Our results are in agreement with those obtained in motor cortex and area 5 (Georgopoulos et al., 1985) and in the premotor cortex (Weinrich and Wise, 1982; Weinrich et al., 1984; Hocherman and Wise, 1989) as well. In addition, our study, through the analysis of these relations across the entire work space, revealed that when 2 spatial variables arc to be dissociatcd, the probability of correctly detecting the one to which cell activity is most closely related depends on the extent of the work space within which the animal performs. In fact, when cell activity was studied in a single part of space, the percentage of cells potentially coding movement end point was higher than that found when cell activity was analyzed throughout the entire work space. In this latter situ- ation, where the number of movement directions tested was significantly increased, only a minority of cells remained candidates for coding only movement end point. Our results also make it improbable that the neuronal populations of the premotor cortex we recorded from in this study might relate to specific goal-directed motor acts (Rizzolatti et al., 1988) independent from the specification of the movement trajectory. The data from this population does not exclude, however, the possibility of the existence of other populations of neurons in the premotor cortex which possess more complex response properties in the context of a more complex behavioral paradigm. In this respect it is interesting that cells with target-related activity independent from the kinematic characteristics of arm movements have been described in supplementary motor cortex, motor cortex, and putamen (Alexander and Crutcher, 1990).

\section{References}

Alexander GE, Crutcher MD (1990) Neural representations of the target (goal) of visually guided arm movements in three motor areas of the monkey. J Neurophysiol 64:164-178.

Andersen RA, Mountcastle VB (1983) The influence of the angle of gaze upon the excitability of the light-sensitive neurons of the posterior parietal cortex. J Neurosci 3:532-548.

Andersen RA, Zipser D (1988) The role of the posterior parietal cortex in coordinate transformations for visual-motor integration. Can $\mathbf{J}$ Physiol Pharmacol 66:445-462.

Andersen RA, Essick GK, Siegel RM (1985) Encoding of spatial location by posterior parietal neurons. Science 230:456-458.

Barbas H, Pandya DN (1987) Architecture and frontal cortical connections of the premotor cortex (area 6) in the Rhesus monkey. J Comp Ncurol 256:211-228.

Brinkman C, Porter R (1983) Supplementary motor area and premotor area of monkey cerebral cortex: functional organization and activities of single neurons during performance of a learned movement. In: Motor control mechanisms in health and disease (Desmedt JE, ed), pp 393-420. New York: Raven.

Caminiti R, Kalaska JF, Georgopoulos AP (1981) Cortical mechanisms of two dimensional aimed arm movements. IV. Effects of arm position in space. Soc Neurosci Abstr 7:563.

Caminiti R, Johnson PB, Urbano A (1990) Making arm movements within different parts of space: dynamic aspects in the primate motor cortex. J Neurosci 10:2039-2058.

Efron B (1979) Bootstrap methods: another look at the jackknife. Ann Statist $7: 1-26$.

Fcldman JA (1981) A connectionist model of visual memory. In: Parallel models of associative memory (Hinton GE, Anderson JA, eds), pp 49-81. Hillsdale: Erlbaum.

Fisher NI, Lee AJ (1983) Correlation coefficients for random variables on a unit sphere or hypersphere. Biometrika 73:159-164.

Fortier PA, Kalaska JF, Smith AM (1989) Cerebellar neuronal activity related to whole-arm reaching movements in the monkey. J Neurophysiol 62:198-211.

Georgopoulos AP, Kalaska JF, Caminiti R, Massey JT (1982) On the relations between the direction of two-dimensional arm movements and cell discharge in primate motor cortex. J Neurosci 2:1527-1537.

Georgopoulos AP, Caminiti R, Kalaska JF, Massey JT (1983) Spatial coding of movement: a hypothesis concerning the coding of movement direction by motor cortical populations. Exp Brain Res (Suppl) 7:327-336.

Georgopoulos AP, Caminiti R, Kalaska JF (1984) Static spatial effects in motor cortex and area 5: quantitative relations in two-dimensional space. Exp Brain Res 54:446-454.

Georgopoulos AP, Kalaska JF, Caminiti R (1985) Relations between two-dimensional arm movements and single-cell discharge in motor cortex and area 5: movement direction versus movement end point. Exp Brain Res 10:175-183.

Georgopoulos AP, Schwartz AB, and Kettner RE (1986) Neuronal population coding of movement direction. Science 233:1416-1419.

Georgopoulos AP, Kettner RE, Schwartz AB (1988) Primate motor cortex and free arm movements to visual targets in three-dimensional space. II. Coding of the direction of movement by a neuronal population. J Neurosci 8:2928-2937. 
Godschalk M, Lemon RN, Nijs HGT, Kuypers HGJM (1981) Behaviour of neurons in monkey peri-arcuate and precentral cortex before and during visually guided arm and hand movements. Exp Brain Res 44:113-116.

Godschalk M, Lemon RN, Kuypers HGJM, Van Der Steen J (1985) The involvement of the monkey premotor cortex neurones in preparation of visually cued arm movements. Behav Brain Res 18:143157.

Hocherman S, Wise SP (1989) Movement trajectory or goal representation in primate premotor and primary motor cortex. Soc Neurosci Abstr 15:789.

Hummelsheim $\mathrm{H}$, Bianchetti $\mathbf{M}$, Wiesendanger $\mathrm{M}$, Wiesendanger $\mathrm{R}$ (1988) Sensory inputs to agranular motor fields: a comparison between precentral, supplementary-motor and premotor areas in the monkey. Exp Brain Res 69:289-298.

Jupp PF, Mardia KV (1980) A general correlation coefficient for directional data and related regression problems. Biometrika 67:163173.

Kalaska JF, Hyde ML (1985) Area 4 and area 5: differences between the load-dependent discharge variability of cells during active postural fixation. Exp Brain Res 59:197-202.

Kaluska JF, Caminiti R, Georgopoulos AP (1983) Cortical mechanisms related to the direction of two-dimensional arm movements: relations in parietal area 5 and comparison with motor cortex. Exp Brain Res 51:347-360.

Kalaska JF, Cohen DAD, Hyde ML, Prud'homme M (1989) A comparison of movement direction-related vs. load direction-related activity in primate motor cortex, using a two-dimensional reaching task. J Neurosci 9:2080-2102.

Kettner RE, Schwartz AB, Georgopoulos AP (1988) Primate motor cortex and free arm movements to visual targets in three-dimensional space. III. Positional gradients and population coding of movement direction from various movement origins. J Neurosci 8:2938-2947.

Kubota K, Hamada I (1978) Visual tracking and neuron activity in the post-arcuate area in monkeys. J Physiol (Paris) 74:297-312.

Kurata K, Tanji J (1986) Premotor cortex neurons in Macaques: activity before distal and proximal forelimb movements. J Neurosci 6: 403-411.

Okano K, Tanji J (1987) Neuronal activities in the primate motor fields of the agranular frontal cortex preceding visually triggered and self-paced movement. Exp Brain Res 66:155-166.

Riehle A, Requin J (1989) Monkey primary motor and premotor cortex: single-cell activity related to prior information about direction and extent of an intended movement. J Neurophysiol 61:534-549.
Rizzolatti G, Scandalora C, Matelli M, Gentilucci M (1981a) Afferent properties of periarcuate neurons in macaque monkey. I. Somatosensory responses. Behav Brain Res 2:125-146.

Rizzolatti G, Scandalora C, Matelli M, Gentilucci M (1981b) Afferent properties of periarcuate neurons in macaque monkey. II. Visual responses. Behav Brain Res 2:147-163.

Rizzolatti G, Camarda R, Fogassi L, Gentilucci M, Luppino G, Matelli $M$ (1988) Functional urganization of inferior area 6 in the macaque monkey. II. Area F5 and the control of distal movements. Exp Brain Res 71:491-507.

Schwartz AB, Georgopoulos AP (1987) Relations between the amplitude of 2-dimensional arm movements and single cell discharge in primate motor cortex. Soc Neurosci Abstr 13:244.

Schwartz AB, Ketter RE, Georgopoulos AP (1988) Primate motor cortex and free arm movements to visual targets in three-dimensional space. I. Relations between single cell discharge and direction of movement. J Neurosci 8:2913-2927.

Sejnowski TJ (1986) Open questions about computation in cerebral cortex. In: Parallel distributed processing (Feldman J $\Lambda$, Hayes PJ, Rumelhart DE, eds), Vol. 2, pp 372-389. Cambridge: MIT Press.

Sessle BJ, Wiesendanger M (1982) Structural and functional definition of the motor cortex in the monkey (Macaca fascicularis). J Physiol (Lond) 323:245-265.

Soechting JF, Flanders M (1989a) Sensorimotor representations for pointing to targets in three-dimensional space. J Neurophysiol 62: 582-594.

Soechting JF, Flanders M (1989b) Errors in pointing are due to approximations in sensorimotor transformations. J Neurophysiol 62: 595-608.

Steinmetz. MA, Motter BC, Duffy CD, Mountcastle VB (1987) Functional properties of parietal visual neurons: radial organization of directionalities within the visual field. J Neurosci 7:177-191.

Vogels R (1990) Population coding of stimulus orientation by striate cortical cells. Biol Cybern 64:25-31.

Weinrich M, Wise SP (1982) The premotor cortex of the monkey. J Neurosci 2:1329-1345.

Weinrich M, Wise SP, Mauritz KH (1984) A neurophysiological study of the premotor cortex in the rhesus monkey. Brain 107:385-414.

Wise SP (1984) The non-primary motor cortex and its role in the cerebral control of movement. In: Dynamic aspects of neocortical function (Edelman GM, Gall WE, Cowan WM, eds), pp 525-555. New York: Neurosciences Institute Press.

Wise SP (1985) The primate premotor cortex fifty years after Fulton. Behav Brain Res 18:79-88. 